\title{
Cribriform-Morular Variant of Papillary Thyroid Carcinoma Shows High Ki-67 Labeling Indices, despite Its Excellent Prognosis
}

\author{
Mitsuyoshi Hirokawa ${ }^{a}$ Katsuya Matsudab Takumi Kudoc Miyoko Higuchi ${ }^{\mathrm{d}}$ \\ Ayana Suzuki $^{d}$ Nami Takadae Masahiro Nakashima ${ }^{b}$ Akira Miyauchi $^{f}$ \\ ${ }^{a}$ Department of Diagnostic Pathology and Cytology, Kuma Hospital, Kobe, Japan; ${ }^{\mathrm{b}}$ Department of Tumor and \\ Diagnostic Pathology, Atomic Bomb Disease Institute, Nagasaki University, Nagasaki, Japan; 'Department of \\ Internal Medicine, Kuma Hospital, Kobe, Japan; ${ }^{d}$ Department of Laboratory Medicine, Kuma Hospital, Kobe, Japan; \\ eDepartment of Diagnostic Pathology, Faculty of Medicine, Oita University, Yufu, Japan; fDepartment of Surgery, \\ Kuma Hospital, Kobe, Japan
}

\section{Keywords}

Papillary thyroid carcinoma. Cribriform-morular variant .

Apoptosis $\cdot \beta$-Catenin $\cdot$ Estrogen receptor

\begin{abstract}
Objective: This study aimed to demonstrate that the cribriform-morular variant (CMV) of papillary thyroid carcinoma (PTC) has high Ki-67 labeling indices, despite its excellent prognosis. Methods: We examined 21 CMV-PTCs and 5 conventional PTCs (C-PTCs) resected at Kuma Hospital between 2008 and 2018. All of the patients with CMV-PTC were women. Their ages ranged from 17 to 35 years, with a mean of 25.2 years. An immunohistochemical study using $\beta$-catenin, estrogen receptor (ER), and Ki-67 was performed. For apoptotic analysis, terminal deoxynucleotidyl transferase-mediated dUTP nick-end labeling staining was performed. $\boldsymbol{R e}$ sults: All CMV-PTCs were encapsulated with thick fibrous connective tissue. Eleven and one CMV-PTCs exhibited capsular invasion and extrathyroidal invasion, respectively. Two patients showed regional nodal metastasis. The Ki-67 labeling index ranged from 4.8 to $36.4 \%$ (mean 15.2\%). Apoptot-
\end{abstract}

(c) 2019 S. Karger AG, Basel

\section{E-Mail karger@karger.com www.karger.com/pat \\ KARGER}

ic cells were counted, which showed 2-52 positive cells (mean 12.6) per 10 high-power fields. The Ki-67 labeling index was positively correlated with the apoptotic cell count $(r=0.48, p=0.030$ ). Ki-67 labeling indices of CMV-PTCs were significantly higher than those of C-PTCs $(p=0.0027)$. Ages and tumor sizes did not have significant correlations with $\mathrm{Ki}$ 67 labeling indices or apoptotic cell counts. Conclusion: This study is the first to demonstrate disproportionally high Ki-67 labeling indexes in a large number of CMV-PTC cases, despite the fact that these cases had favorable prognoses. The favorable prognosis of CMV-PTC may be attributable to encapsulation and nuclear ER expression.

(c) 2019 S. Karger AG, Basel

\section{Introduction}

The cribriform-morular variant (CMV) of papillary thyroid carcinoma (PTC) is a rare subtype of PTC, and accounts for $<0.5 \%$ of all PTCs [1-4]. It usually occurs in young women and is commonly associated with familial adenomatous polyposis (FAP) $[1,2,4,5]$. However, a 
Table 1. Characteristics of the examined CMV and C-PTCs

\begin{tabular}{lll}
\hline & $\begin{array}{l}\text { CMV-PTC } \\
(n=21)\end{array}$ & $\begin{array}{l}\text { C-PTC } \\
(n=5)\end{array}$ \\
\hline $\begin{array}{l}\text { Female:male, } n \\
\text { Age, years }\end{array}$ & $21: 0$ & $5: 0$ \\
Familial adenomatous polyposis & $25.2(17-35)$ & $34.8(26-55)$ \\
$\quad$ Present & $7(33.3)$ & - \\
$\quad$ Absent & $12(57.1)$ & - \\
$\quad$ Unknown & $2(9.5)$ & - \\
Size, mm & $27.1(9-50)$ & $27.6(18-42)$ \\
Encapsulated & $21(100)$ & $1(20.0)$ \\
$\quad$ With capsular invasion & $11(52.4)$ & $1(100)$ \\
Extrathyroidal invasion & $1(4.8)$ & $3(60.0)$ \\
Nodal metastasis & $2(9.5)$ & $5(100)$ \\
$\beta$-Catenin (nuclear expression) & $21(100)$ & $0(0)$ \\
ER & $21(100)$ & $0(0)$ \\
Ki-67 labeling index, \% & $15.2(4.8-36.4)$ & $3.1(1-6.5)$ \\
TUNEL staining & $(n=20)$ & $(n=5)$ \\
$\quad$ Apoptotic cells/10 HPF & $12.6(2-52)$ & $10.8(4-21)$ \\
\hline
\end{tabular}

Data are presented as the mean (range) or $n(\%)$. CMV-PTC, cribriform-morular variant of papillary thyroid carcinoma; C-PTC, conventional papillary thyroid carcinoma; ER, estrogen receptor; TUNEL, terminal deoxynucleotidyl transferase (TdT)-mediated dUTP nick-end labeling; HPF, high-power fields. sporadic form of CMV-PTC without FAP has also been reported $[1,2,6]$. Sporadic CMV-PTCs usually appear as a solitary nodule, while FAP-associated CMV-PTCs are frequently multifocal $[6,7]$. The prevalence rates of nodal metastases ( 12 vs. $43 \%$ ) and recurrence ( 9 vs. $16 \%$ ) are lower in CMV-PTC than in conventional PTC (C-PTC) $[1,2]$. Thus, patients with CMV-PTC have a low mortality rate and an excellent prognosis.

The Ki-67 labeling index has been used extensively as a proliferation marker. A high Ki-67 labeling index usually indicates aggressive behavior or poor prognosis [810]. More than $90 \%$ of patients with PTC have a low Ki67 labeling index $(<3 \%)$, and those patients with Ki-67 labeling indices $>3 \%$ have significantly worse cause-specific survival [9]. Miyauchi et al. [10] reported that the Ki-67 labeling indices of aggressive-type PTCs were significantly higher than those of C-PTCs. However, Brehar et al. [11] reported a case of CMV-PTC that had a high Ki-67 labeling index (15\%), despite its excellent prognosis. To the best of our knowledge, no study focusing on this discrepancy has been reported. We hypothesized that the favorable prognosis of CMV-PTCs may be due to their extremely high frequencies of apoptotic cells. Accordingly, we attempted to count apoptotic cells in CMV-PTCs. This study aimed to demonstrate that CMV-PTCs show high Ki-67 labeling indices, despite their excellent prognosis. The study also includes discussion of the discrepancy between Ki-67 labeling indices and prognosis.

\section{Materials and Methods}

We extracted 21 CMV-PTCs resected at Kuma Hospital between 2008 and 2018. A histological diagnosis of CMV-PTC was made on the basis of the following criteria: (1) papillary growth composed of tall columnar cells, (2) cribriform architecture without colloid, (3) solid and spindle cell areas, (4) morules, and (5) peculiar nuclear clearing. All of the patients with CMV-PTC were women. Their ages ranged from 17 to 35 years, with a mean of 25.2 years. In this study, we also included 5 C-PTCs recently resected at Kuma Hospital as controls. All of the patients with C-PTC were women. Their ages ranged from 26 to 55 years, with a mean of 34.8 years. Clinical data were obtained from patient medical records at Kuma Hospital.

For immunohistochemical and apoptotic analysis, representative tissue blocks were selected. In 7 cases with multiple CMV-PTC nodules, the largest nodule was selected for evaluation in this study. Immunohistochemical staining was performed using the automated Leica Bond-Max system and Bond Refine detection kit (Leica Microsystems, Wetzlar, Germany) according to the manufacturer's recommendations. We used primary antibodies against Ki-67 (MIB-1, 1:200 dilution, Dako, Glostrup, Denmark), $\beta$-catenin ( $\beta$-catenin 1, 1:200; Dako, Carpinteria, CA, USA) and estrogen receptor (ER; 6F11, 1:400; Novocastra, Newcastle, UK). The Ki-67 labeling index was estimated by counting at least 500 
carcinoma cells in the hot spot. Terminal deoxynucleotidyl transferase (TdT)-mediated dUTP nick-end labeling (TUNEL) staining was performed using the ApopTag ${ }^{\circledR}$ peroxidase in situ apoptosis detection kit (Millipore, Temecula, CA, USA). Silanized, 3- $\mu$ m sections were deparaffinized and digested with proteinase $\mathrm{K}(18 \mu \mathrm{g} /$ $\mathrm{mL}$ ) for $15 \mathrm{~min}$ at room temperature. Endogenous peroxidase activity was blocked with $3 \%$ hydrogen peroxide. The sections were incubated with $\mathrm{TdT}$ in reaction buffer containing a fixed concentration of digoxigenin-labeled nucleotides for $1 \mathrm{~h}$ at $37^{\circ} \mathrm{C}$. The reactions were terminated by incubating slides in stop/wash buffer for $10 \mathrm{~min}$. Then, the sections were incubated with anti-digoxigenin peroxidase for $30 \mathrm{~min}$, and apoptotic cells were detected after incubation in DAB for 10 min and counterstaining with Mayer's hematoxylin solution for $3 \mathrm{~min}$. The slides were observed at $\times 200$ magnification, and the counts of TUNEL-positive cells (apoptotic cells) were determined in 10 fields per slide.

Statistical analyses were performed using the Stat Flex v.6 statistical software (Artech Co. Ltd, Osaka, Japan). Values of $p<0.05$ were regarded as statistically significant in the Fisher probability test and Student's $t$ test.

\section{Results}

Table 1 summarizes the case characteristics and examination results for the $21 \mathrm{CMV}$-PTCs and 5 C-PTCs. Seven CMV-PTC patients had colonic polyposis, while 12 did not. The remaining 2 patients have not undergone colonic examination. Multiple nodules were found in 7 patients with CMV-PTC, including 5 patients with polyposis, 1 patient without polyposis, and 1 polyposis-unknown patient. Tumor sizes were measured by ultrasound examination and varied from 9 to $50 \mathrm{~mm}$ in their greatest dimension, with a mean of $27.1 \mathrm{~mm}$. All CMVPTCs were well encapsulated with thick fibrous connective tissue (Fig. 1a). Histologically, 11 nodules (52.4\%) showed capsular invasion but were not widely invasive (Fig. 1b). Only one nodule revealed extrathyroidal invasion. Two patients showed regional nodal metastasis, 1 of whom was the patient with extrathyroidal invasion. None of the cases included distant metastasis at the time of CMV-PTC diagnosis.

Immunohistochemically, all of the CMV-PTCs showed nuclear and cytoplasmic $\beta$-catenin expression (Fig. 2a), as well as nuclear ER expression (Fig. 2b). All of the C-PTCs showed cell membrane expression for $\beta$-catenin without nuclear ER expression. Ki-67 labeling indices ranged from 4.8 to $36.4 \%$ (mean $15.2 \%$; Fig. $3 a$ ). The Ki-67 labeling indices of CMV-PTCs were significantly higher than those of C-PTCs $(p=0.0027)$. The high Ki-67 labeling indices ( $>10 \%$ ) were not related to age, tumor size, or presence of FAP. Nuclei with peculiar nuclear clearing were negative for Ki-67. Mitotic figures were
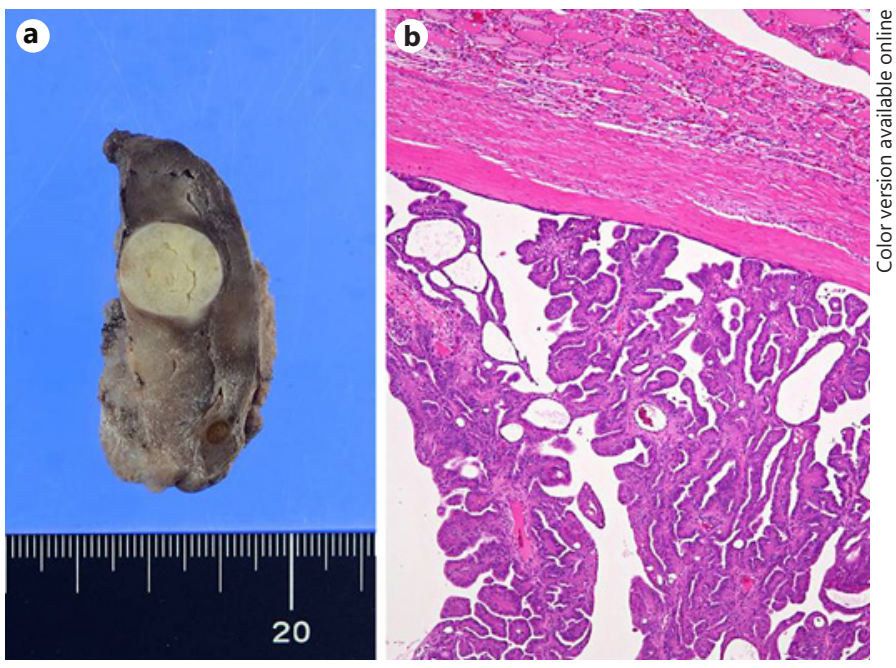

Fig. 1. Case 6. a Gross finding: the CMV of PTC was well encapsulated. b Microscopically, capsular invasion was evident. Hematoxylin and eosin stain, $\times 40$.
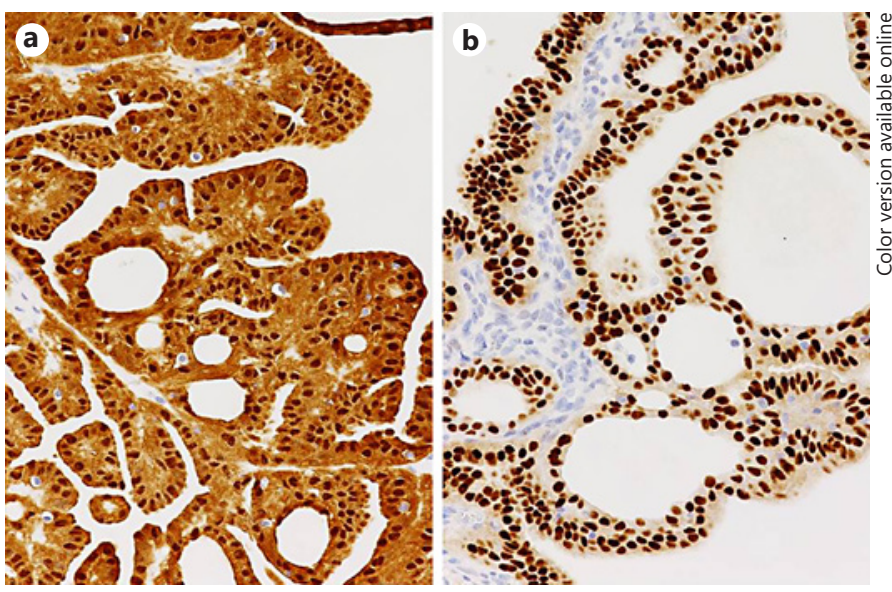

Fig. 2. Case 6. Immunohistochemically, carcinoma cells of the CMV of PTC showed nuclear and cytoplasmic expression for $\beta$-catenin $(\mathbf{a} ; \times 200)$ and nuclear expression for ER $(\mathbf{b} ; \times 200)$.

not observed in all cases. Apoptotic cells were evaluated in CMV-PTCs of 20 patients, which showed counts of 2-52 positive cells (mean 12.6) per 10 high-power fields (Fig. 3b). Apoptotic cells were also evaluated in the CPTCs, which showed counts of 4-21 (mean 10.8\%) per 10 high-power fields. The apoptotic cell counts of the CMVPTCs and C-PTCs were not significantly different. In the CMV-PTCs, the Ki-67 labeling index was positively correlated with apoptotic cell count $(r=0.48, p=0.030$; Fig. 4). Age, tumor size, polyposis status, extrathyroidal invasion, and nodal metastasis showed no significant correlations with the Ki-67 labeling index or apoptotic cells. 

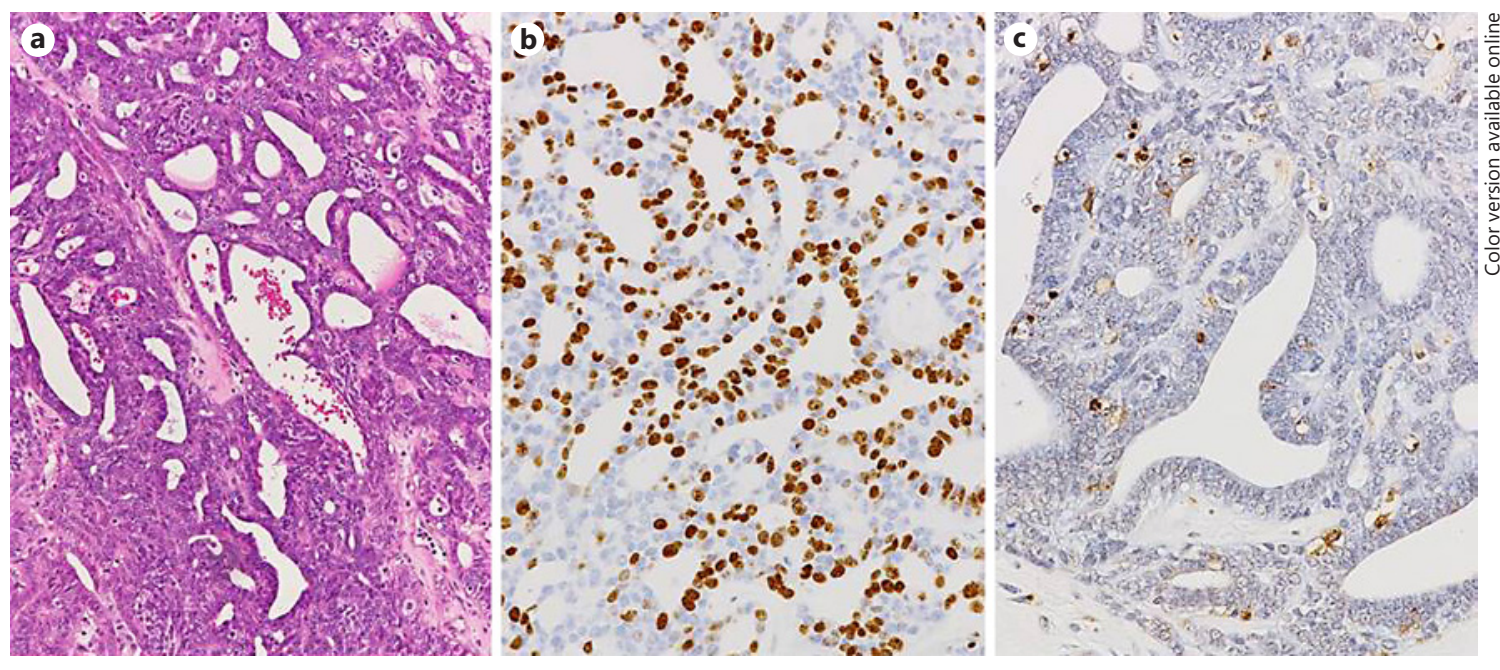

Fig. 3. Case 5 . a Hematoxylin and eosin stain, $\times 100$. b The CMV of PTC showed a Ki-67 labeling index of $36.4 \%$. Immunostaining for Ki-67, $\times 200$. c The apoptotic cell count was 21 per 10 high-power fields. TUNEL staining, $\times 200$.

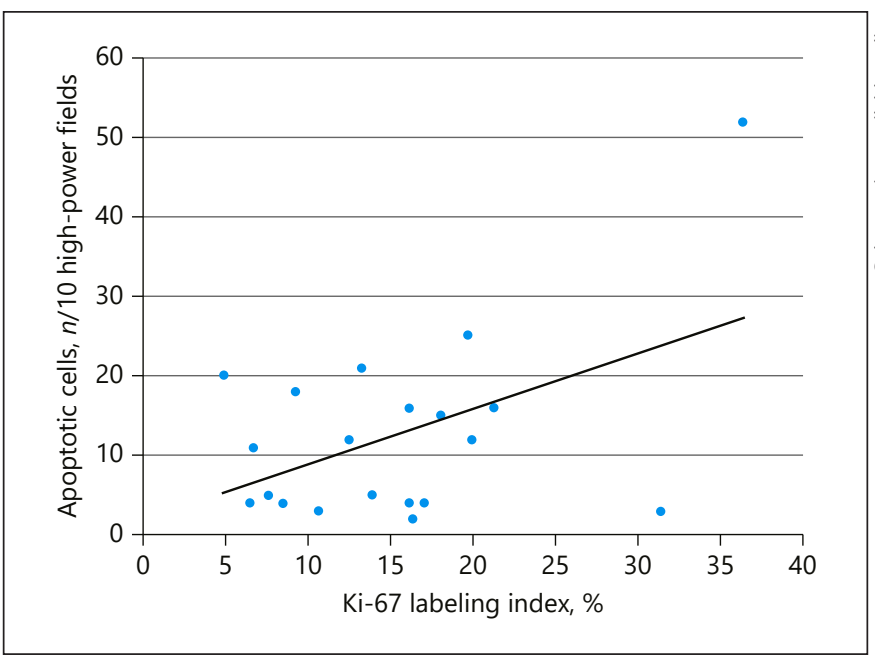

Fig. 4. The correlation between Ki-67 labeling indices and apoptotic cell counts in cases of the CMV of PTC.

\section{Discussion}

$\mathrm{Ki}-67$ protein is a nuclear antigen that is present during all active phases of the cell cycle (G1, S, G2, and mitosis), but is usually absent in quiescent cells (G0) [12]. The $\mathrm{Ki}-67$ labeling index has been used extensively as a proliferation marker for a wide variety of tumors. A high Ki67 labeling index usually indicates aggressive behavior, high-grade malignancy, and/or poor prognosis [8-10]. The Ki-67 labeling index is low $(<3 \%)$ in more than $90 \%$ of PTCs, and those patients who have PTC with a Ki-67 labeling index $>3 \%$ show significantly worse cause-specific survival [9]. Additionally, Ki-67 labeling indices are significantly higher in aggressive-type PTCs than in conventional-type PTCs $[10,13,14]$.

In this study, we showed that Ki-67 labeling indices in CMV-PTCs ranged from 4.8 to $36.4 \%$ (mean 15.2\%). PTCs presenting such high Ki-67 labeling indices have generally been regarded as aggressive $[10,13,14]$. Our cases, however, showed low incidences of extrathyroidal invasion and regional nodal metastasis. Further, none of the cases showed distant metastasis at the time of the diagnosis. Similarly, it has previously been reported that CMV-PTC cases have lower rates of nodal metastases at presentation (12\%), distant metastases at presentation (3\%), recurrence (8.5\%), and mortality (2\%) in comparison with cases of C-PTC [2]. Brehar et al. [11] reported 1 case of CMV-PTC that had a Ki-67 labeling index of 15\% but showed a good prognosis. In the current study, we have provided the first demonstration that there is a general discrepancy between the high Ki-67 labeling indices and favorable behavior of CMV-PTCs. If high Ki-67 labeling indices are directly related to high proliferation of carcinoma cells, CMV-PTCs should exhibit mitotic figures; however, mitotic figures were not observed in all cases. The reason for this discrepancy is not clear. It is important to remember that a high Ki-67 labeling index indicates aggressive behavior, high-grade malignancy, and/or poor prognosis - except in cases of CMV-PTC.

False positive reactions, caused by either endogenous biotin or other chemical compounds with high affinity 
for avidin, can occur in immunohistochemical staining [15]. False positive reactions may occur in Ki-67 immunostaining because the nuclei with particular nuclear clearing have rich biotin. However, the immunostaining technique used in this study did not include avidin or streptavidin. In addition, nuclei with peculiar nuclear clearing were negative for Ki-67. Therefore, we can assert the reliability of the Ki-67 labeling indices noted in the current study.

We think that several factors could be responsible for the favorable behavior of CMV-PTCs. Most CMV-PTCs are encapsulated or well circumscribed, and may present capsular invasion $[2,6]$. All of the CMV-PTCs that we studied were encapsulated, and $52.4 \%$ of them showed capsular invasion without widespread invasion. Encapsulated PTC exhibits a more indolent biologic behavior than C-PTC $[16,17]$. Therefore, encapsulation may be one of the factors responsible for CMV-PTC's favorable prognosis.

Apoptosis plays a crucial role in developing and maintaining the health of the body by eliminating old cells, unnecessary cells, and cancerous cells [18]. The balance between proliferation and apoptosis may be involved in determining the growth and aggressiveness of tumors [19]. Frequencies of apoptotic cells are significantly lower in anaplastic thyroid carcinomas than in PTCs [19]. We hypothesized that the favorable prognosis of CMV-PTC may be due to their extremely high frequencies of apoptotic cells. In this study, we used TUNEL staining as a method of detecting apoptosis. The results showed no significant difference in apoptotic cell counts between CMV-PTCs and C-PTCs. The lack of a significant difference might simply be a consequence of the small size of the C-PTC group. Ki-67 labeling indices and apoptotic cell counts were positively correlated. Many studies have consistently reported a positive correlation or association between apoptosis and proliferation, and generally the extent of apoptosis is not associated with survival [20]. Thus, we failed to demonstrate our hypothesis.

Immunohistochemically, nuclear $\beta$-catenin expression is characteristic of CMV-PTC, and this reactivity is not observed in C-PTC $[2,3,11,21]$. $\beta$-Catenin is a component of the Wnt signaling pathway, and its nuclear accumulation has been shown to play an important role in tumorigenesis and increased cell proliferation [22]. Nuclear $\beta$-catenin accumulation is related to invasion, metastasis, and poor prognosis in colorectal cancers [23]. Therefore, this phenomenon does not seem to be directly involved in the favorable prognosis of CMV-PTC.
Nuclear ER expression is frequently observed in CPTCs $[24,25]$ and always observed in CMV-PTCs [2, 21]. Estrogen is a potent growth factor for PTC, and this growth is promoted via the ER [25]. In a study of thyroid tumors, Vannucchi et al. [26] reported that ER positivity has a significant association with larger tumor size and tends to be associated with a higher prevalence of local metastases. They also reported a high prevalence of $B R A F^{V 600 E}$ mutations in ER-expressing tumors [26]. CMV-PTCs that are positive for nuclear ER expression occur exclusively in women, and probably proliferate in the presence of estrogen. Based on these findings, the presence of nuclear ER expression does not seem to be related to the favorable prognosis of CMV-PTC. However, it is interesting that CMV-PTCs are not found after the age of 40 years, when serum estrogen physiologically decreases [27]. The fact that CMV-PTC has not been documented in older patients may indicate that spontaneous regression is possible, as has been observed in cases of neuroblastoma [28].

In conclusion, this study was the first to demonstrate disproportionally high Ki-67 labeling indexes in a large number of CMV-PTC cases, despite the fact that these cases had favorable prognoses. The favorable prognosis of CMV-PTC may be attributable to encapsulation and nuclear ER expression. A limitation of this study is that it relied on only 1 of the several available methods for detecting apoptosis. Further apoptosis-related investigations are required to clarify the nature of the Ki-67 discrepancy in cases of CMV-PTC, such as studies using the in situ nick translation method, or immunostaining for cleaved caspase 3, cleaved PARP, and single-stranded DNA.

\section{Statement of Ethics}

The study protocol was approved by the Institutional Review Board of Kuma Hospital, Hyogo, Japan (approval No. 20180913-1).

\section{Disclosure Statement}

The authors have no conflicts of interest to declare regarding grant support or financial relationships. 


\section{References}

1 Sak SD. Variants of papillary thyroid carcinoma: multiple faces of a familiar tumor. Turk Patoloji Derg. 2015;31(suppl 1):34-47.

2 Lam AK, Saremi N. Cribriform-morular variant of papillary thyroid carcinoma: a distinctive type of thyroid cancer. Endocr Relat Cancer. 2017 Apr;24(4):R109-21.

3 Hirokawa M, Maekawa M, Kuma S, Miyauchi A. Cribriform-morular variant of papillary thyroid carcinoma-cytological and immunocytochemical findings of 18 cases. Diagn Cytopathol. 2010 Dec;38(12):890-6.

4 Tomoda C, Miyauchi A, Uruno T, Takamura Y, Ito Y, Miya A, et al. Cribriform-morular variant of papillary thyroid carcinoma: clue to early detection of familial adenomatous polyposis-associated colon cancer. World J Surg. 2004 Sep;28(9):886-9.

5 Harach HR, Williams GT, Williams ED. Familial adenomatous polyposis associated thyroid carcinoma: a distinct type of follicular cell neoplasm. Histopathology. 1994 Dec; 25(6):549-61.

6 Cameselle-Teijeiro J, Chan JK. Cribriformmorular variant of papillary carcinoma: a distinctive variant representing the sporadic counterpart of familial adenomatous polyposis-associated thyroid carcinoma? Mod Pathol. 1999 Apr;12(4):400-11.

7 Miyaki M, Iijima T, Ishii R, Hishima T, Mori $\mathrm{T}$, Yoshinaga K, et al. Molecular evidence for multicentric development of thyroid carcinomas in patients with familial adenomatous polyposis. Am J Pathol. 2000 Dec;157(6): $1825-7$.

8 Kjellman P, Wallin G, Höög A, Auer G, Larsson C, Zedenius J. MIB-1 index in thyroid tumors: a predictor of the clinical course in papillary thyroid carcinoma. Thyroid. 2003 Apr; 13(4):371-80.

9 Ito Y, Miyauchi A, Kakudo K, Hirokawa M, Kobayashi K, Miya A. Prognostic significance of ki-67 labeling index in papillary thyroid carcinoma. World J Surg. 2010 Dec;34(12): 3015-21.
10 Miyauchi A, Kudo T, Hirokawa M, Ito Y, Kihara M, Higashiyama T, et al. Ki-67 labeling index is a predictor of postoperative persistent disease and cancer growth and a prognostic indicator in papillary thyroid carcinoma. Eur Thyroid J. 2013 Mar;2(1):57-64.

11 Brehar AC, Terzea DC, Ioachim DL, Procopiuc $\mathrm{C}$, Brehar FM, Bulgăr $\mathrm{AC}$, et al. Cribriform-morular variant of papillary thyroid carcinoma at pediatric age - case report and review of the literature. Rom J Morphol Embryol. 2016;57(2):531-7.

12 Wallin G, Bäckdahl M, Christensson B, Grimelius L, Auer G. Nuclear protein content and Ki-67 immunoreactivity in nonneoplastic and neoplastic thyroid cells. Anal Quant Cytol Histol. 1992 Aug;14(4):296-303.

13 Ito Y, Hirokawa M, Miyauchi A, Higashiyama T, Kihara M, Miya A. Prognostic significance of the proportion of tall cell components in papillary thyroid carcinoma. World J Surg. 2017 Mar;41(3):742-7.

14 Cameselle-Teijeiro JM, Rodríguez-Pérez I, Celestino R, Eloy C, Piso-Neira M, Abdulkader-Nallib I, et al. Hobnail variant of papillary thyroid carcinoma: clinicopathologic and molecular evidence of progression to undifferentiated carcinoma in 2 cases. Am J Surg Pathol. 2017 Jun;41(6):854-60.

15 Nikiel B, Chekan M, Jarząb M, Lange D. Endogenous avidin biotin activity (EABA) in thyroid pathology: immunohistochemical study. Thyroid Res. 2009 Apr;2(1):5.

16 Pisanu A, Deplano D, Reccia I, Porceddu G, Uccheddu A. Encapsulated papillary thyroid carcinoma: is it a distinctive clinical entity with low-grade malignancy? J Endocrinol Invest. 2013 Feb;36(2):78-83.

17 Ito $\mathrm{Y}$, Hirokawa $\mathrm{M}$, Uruno T, Kihara $\mathrm{M}$, Higashiyama T, Takamura Y, et al. Biological behavior and prognosis of encapsulated papillary carcinoma of the thyroid: experience of a Japanese hospital for thyroid care. World J Surg. 2008 Aug;32(8):1789-94.
18 Singh N, Anand S. Apoptosis in health and disease. Indian J Physiol Pharmacol. 1995 Apr;39(2):91-4.

19 Rubin LL, Philpott KL, Brooks SF. Apoptosis: the cell cycle and cell death. Curr Biol. 1993 Jun;3(6):391-4.

20 Soini Y, Pääkkö P, Lehto VP. Histopathological evaluation of apoptosis in cancer. Am J Pathol. 1998 Oct;153(4):1041-53.

21 Cameselle-Teijeiro JM, Peteiro-González D, Caneiro-Gómez J, Sánchez-Ares M, Abdulkader I, Eloy C, et al. Cribriform-morular variant of thyroid carcinoma: a neoplasm with distinctive phenotype associated with the activation of the WNT/ $\beta$-catenin pathway. Mod Pathol. 2018 Aug;31(8):1168-79.

22 MacDonald BT, Tamai K, He X. Wnt/betacatenin signaling: components, mechanisms, and diseases. Dev Cell. 2009 Jul;17(1):9-26.

23 Mårtensson A, Oberg A, Jung A, Cederquist K, Stenling R, Palmqvist R. Beta-catenin expression in relation to genetic instability and prognosis in colorectal cancer. Oncol Rep. 2007 Feb; 17(2):447-52.

24 Jalali-Nadoushan MR, Amirtouri R, Davati A, Askari S, Siadati S. Expression of estrogen and progesterone receptors in papillary thyroid carcinoma. Caspian J Intern Med. 2016;7(3): 183-7.

25 Derwahl M, Nicula D. Estrogen and its role in thyroid cancer. Endocr Relat Cancer. 2014 Oct;21(5):T273-83.

26 Vannucchi G, De Leo S, Perrino M, Rossi S, Tosi D, Cirello V, et al. Impact of estrogen and progesterone receptor expression on the clinical and molecular features of papillary thyroid cancer. Eur J Endocrinol. 2015 Jul; 173(1):29-36.

27 Cutler WB, Genovese-Stone E. Wellness in women after 40 years of age: the role of sex hormones and pheromones. Dis Mon. 1998 Sep;44(9):421-546.

28 Challis GB, Stam HJ. The spontaneous regression of cancer. A review of cases from 1900 to 1987. Acta Oncol. 1990;29(5):545-50. 